\title{
Comparison Of Three Different Treatment Methods For Cesarean Scar Pregnancy
}

This article was published in the following Dove Press journal:

Therapeutics and Clinical Risk Management

\author{
Hui Fei ${ }^{1, *}$ \\ Xuefeng Jiang ${ }^{2, *}$ \\ Tian $\mathrm{Li}^{1}$ \\ Ying $\operatorname{Pan}^{2}$ \\ Hongling Guo' \\ Xiaoyu Xu' \\ Shanrong Shu (iD) ${ }^{2}$ \\ 'Department of Gynecology and \\ Obstetrics, The Seventh Affiliated \\ Hospital of Sun Yat-Sen University, \\ Shenzhen 518107, People's Republic of \\ China; ${ }^{2}$ Department of Gynecology and \\ Obstetrics, The First Affiliated Hospital \\ of JiNan University, Guangzhou 510630 \\ People's Republic of China
}

*These authors contributed equally to this work
Correspondence: Shanrong Shu Department of Gynecology and Obstetrics, The First Affiliated Hospital of JiNan University, 613 Huangpu Road

West, Guangzhou 510630, People's

Republic of China

Tel +86-20-38688769

Fax +86-20-38688769

Email butterfly1705@I26.com
Background/Aim: Cesarean scar pregnancy is a long term complication of cesarean section. There is a lot of controversy about the best treatment methods. We retrospectively summarized the clinical characteristics of patients with cesarean scar pregnancy and explored the advantages and disadvantages of fertility-preservation treatment method.

Methods: From January 2008 to September 2017, a total of 204 cases of cesarean scar pregnancy were retrospectively reviewed. 145 patients underwent transvaginal clearance, 33 patients underwent endoscopic surgery, and 26 patients underwent uterine artery embolism. The clinical characteristics, diagnosis, various treatment methods, and clinical outcomes were analyzed.

Results: There were no significant differences among the three groups in terms of patient age, number of previous cesarean sections, serum human chorionic gonadotropin, and clinical symptoms. The difference in mean gestational sac diameter $(23.5 \pm 2.1 \mathrm{~mm}$ vs 31.3 $\pm 2.4 \mathrm{~mm}$ vs $30.8 \pm 1.9 \mathrm{~mm})$, surgical time $(31.4 \pm 2.5 \mathrm{~min}$ vs. $45.8 \pm 2.2 \mathrm{~min}$ vs. $51.4 \pm 1.9 \mathrm{~min})$, blood loss $(53.3 \pm 5.5 \mathrm{~mL}$ vs. $105.2 \pm 3.2 \mathrm{~mL}$ vs. $75.6 \pm 3.5 \mathrm{~mL})$, blood transfusion $(1 / 145$ case vs. $3 / 33$ case vs. $0 / 26$ case), discomfort ( $1 / 145$ case vs. $9 / 33$ case vs. $16 / 26$ case), hospital stay (6.1 \pm 1.1 day vs. $7.4 \pm 0.9$ day vs. $18.6 \pm 1.5$ day), fever duration ( $1.0 \pm 0.5$ day vs. $2.1 \pm 2.8$ day vs. $5.7 \pm 3.5$ day), and hospital expense ( $¥ 7825.9 \pm 234.9$ vs. $¥ 10248.3 \pm 312.9$ vs. $¥ 18774.9$ \pm 243.6 ) in transvaginal pregnancy tissue clearance, endoscopic surgery, and uterine artery embolism groups were significantly different.

Conclusion: Transvaginal clearance is an effective and relatively safe treatment option for patients with cesarean scar pregnancy.

Keywords: cesarean scar pregnancy, transvaginal clearance, endoscopy, uterine artery embolism

\section{Introduction}

Cesarean scar pregnancy (CSP) is defined as the embryo implanting in the previous cesarean section scar, which is a long-term postoperative complication of a cesarean section, accounting for $0.45 \%$ of complications due to cesarean section. ${ }^{1}$ With the rising rate of cesarean section and the improvement of diagnostic technique, the incidence of CSP has substantially increased worldwide. ${ }^{2}$ Especially in China, with the opening of two-child policy, it was estimated that 1 in 531 women with a previous cesarean scar will have CSP. ${ }^{3}$ Though the diagnosis of CSP is not difficult, early suspicion is very necessary because misdiagnosis may bring about severe life threatening complications, such as uterine rupture, severe bleeding, and even hysterectomy leading to loss of fertility.

Usually, CSP is manipulated by conservative intervention or surgical treatment, or a combination of the two approaches. Several types of conservative treatment 
have been used to treat CSP, like dilation and curettage (D\&C), local or systemic administration of methotrexate, and selective uterine artery embolization with curettage and/or methotrexate administration. ${ }^{4-8}$ Surgical treatment for fertility preservation includes removal of pregnancy tissue and reparation of the scar through conventional open surgery, transvaginal procedure and hysteroscopic or laparoscopic approach. ${ }^{9-11}$

Though many modalities are reported to treat CSP, no universal agreement on the best treatment method or standard treatment protocol has been established until now. ${ }^{12}$ In this study, we presented the clinical characteristics and three different types of management of CSP in our hospital in the hope of providing constructive information to deal with this disease.

\section{Subjects And Methods Patients And Design}

This was a retrospective study of 204 cases diagnosed as CSP in our hospital during January 2008 and September 2017. The diagnostic criteria ${ }^{5}$ was as follows: 1) both the uterine cavity and cervical canal were empty; 2) location of the gestational sac or mixed-echo mass in the anterior wall of the uterine isthmus or in the cesarean scar defect; 3) a diminished myometrium between the bladder wall and the sac or the mass, or a discontinuity in the anterior uterine muscular tissues.

We retrospectively reviewed these patients, all these cases were confirmed by postoperative histopathology. Among the 204 cases, 145 patients received transvaginal pregnancy tissue clearance, 33 cases received endoscopic surgery, and 26 cases received uterine artery embolism with methotrexate administration. The choice of the surgical treatment was based on the conditions of patients, such as the value of serum human chorionic gonadotropin ( $\beta$ $\mathrm{HCG}$ ), the diameter and the specific location of the sac. Clinical data, the value of $\beta-\mathrm{HCG}$, the diameter of gestational sac, operation time and expense, blood loss, and hospital stay were all recorded and analyzed. This study was undertaken with ethical approval of the Human Ethics Committee of Sun Yat-Sen University, which was in accord with the Declaration of Helsinki. All of the enrolled patients signed informed consent.

The statistical software package SPSS 23.0 was used for data analyses. The data were presented as mean \pm standard deviation $( \pm \mathrm{SD})$. Comparisons among all groups were performed with the one-way analysis of variance test.
Meanwhile, a form regression analysis was taken when necessary. If statistical significance was found, the Tukey post hoc test was used. $\mathrm{p}<0.05$ was considered to be statistically significant.

\section{Treatment Methods Transvaginal Cesarean Scar Pregnancy Tissue Clearance}

The patients were placed in dorsal lithotomy position and received spinal and epidural combined anesthesia. Urine was drained by an $12 \mathrm{Fr}$ Foley catheter. We used cervical forceps to tract the upper lip of the cervix to completely expose the anterior fornix. The space between cervix and vagina was injected with adrenaline $0.2 \mathrm{mg}$ diluted in $10 \mathrm{~mL}$ saline to achieve water pressure separation. The vaginal mucosa was cut transversely at the bladder's lateral groove. The peritoneum was opened after the separation of bladder uterine space. The lesion was fully exposed after the vaginal hook was inserted. The myometrium was injected with pituitrin $6 \mathrm{u}$ diluted in $20 \mathrm{~mL}$ saline, then the pregnancy tissues were cleared by suction curettage. After being rinsed and trimmed, the wound was sutured with Vicryl thread.

\section{Endoscopic Surgery}

The patients received general anesthesia. The procedure was similar to general laparoscopy. First we opened the bladder uterus reflexive peritoneum and pushed the bladder down. Then, vasopressin $6 \mathrm{u}$ diluted in $10 \mathrm{~mL}$ saline was administered to determine the uterine scar pregnancy lesions, ultrasonic knife was adopted to cut the myometrium. Lastly, we removed the pregnancy tissue, rinsed and trimmed the uterine defect, and sutured the wound. Meanwhile, hysteroscopy was used to explore the uterine cavity. When it was necessary, we resected remnant pregnancy lesion by hysteroscopy.

\section{Uterine Artery Embolism With Methotrexate}

The patients received spinal and epidural combined anesthesia, then uterine artery embolism (UAE) was performed by experienced radiologists. The catheters were correctly placed and 50mg of methotrexate (MTX) was simultaneously administrated with gelatin sponge particles during the embolism procedure. After the intervention, the patients had no blood loss, just a little errhysis at the puncture point. 


\section{Results}

The clinical characteristics of the patients were presented in Table 1. As shown in the table, the mean age of the 204 patients was $32.3 \pm 6.023$ years, and their mean gravidity and parity were $1.9 \pm 2$ and $1.3 \pm 1$ respectively. The number of previous cesarean section (CS) was checked. 167 (81.86\%) patients had undergone one CS, 33 (16.18\%) had undergone two CS and 4 (1.96\%) had experienced myomectomy before the first delivery. The mean interval from the last CS was $4.2 \pm 3.674$ years with the range from 1 year to 10 years. There was no significant difference in terms of the previously mentioned parameters in the three different procedure groups. But the diameter of the gestational sac was significantly different: $23.5 \pm 2.1 \mathrm{~mm}, 31.3 \pm 2.4 \mathrm{~mm}$, and 30.8 $\pm 1.9 \mathrm{~mm}$ in transvaginal clearance, endoscopic surgery, and UAE respectively.

All patients had vaginal bleeding with or without abdominal pain and a history of amenorrhea with the average time of $67.3 \pm 6.8$ days (range $30 \sim 122$ days). 43 (20.81\%) cases had no symptoms and were diagnosed by routine transvaginal ultrasound, $26(12.75 \%)$ cases were misdiagnosed as early intrauterine pregnancy and underwent artificial abortion resulting in massive bleeding, of which 4 cases were transferred to our hospital. Before intervention, the range of serum $\beta$-HCG was $235 \sim 693,946 \mathrm{IU} / \mathrm{L}$ with the average value of $13,217 \pm 216.8 \mathrm{IU} / \mathrm{L}$. There were no significant differences in the previously mentioned parameters in the three groups.
145 cases were primarily treated with transvaginal pregnancy tissue removal. Among them, only one patient needed extra methotrexate administration for slow decline of serum $\beta$-HCG. 32 cases who were treated with endoscopy received medicine intervention before surgery for high serum $\beta$-HCG, of which 8 received MTX followed by laparoscopic surgery and 24 cases received MTX and mifepristone followed by hysteroscopic surgery. Direct hysteroscopic surgery was performed on one case with relatively lower serum $\beta$-HCG (7IU/L). UAE with local MTX (50mg) was used in 26 cases. After surgery, 7 cases experienced massive bleeding $(500 \mathrm{~mL})$. Among the transvaginal pregnancy tissue removal group, endoscopic surgery group, and UAE group, there were significant differences in blood loss, operation time, hospitalization (days), duration of fever, and hospital expense. Meanwhile, the transvaginal pregnancy tissue removal group had the lowest incidence of the previously mentioned parameters.

In terms of post-operative complications, most cases had no discomfort except for chill after operation in the transvaginal clearance group. 9 patients experienced abdominal pain, dizziness, and shortness of breath in endoscopic surgery group. But in UAE group, 7 cases experienced lower abdominal pain, 6 cases experienced nausea and vomiting, and 3 patients had moderate bone marrow inhibition. What is more, for the 4 patients with increased serum $\beta$-HCG, we performed D\&C (shown in Table2).

Table I Baseline Clinical Characteristics Of Patients In The Three Groups

\begin{tabular}{|c|c|c|c|c|}
\hline \multirow[t]{2}{*}{ Variables } & \multicolumn{3}{|c|}{ Types Of Surgery For CSP } & \multirow[t]{2}{*}{$P$ value } \\
\hline & $\begin{array}{l}\text { Transvaginal Clearance } \\
\text { (145) }\end{array}$ & $\begin{array}{l}\text { Endoscopic Surgery } \\
\text { (33) }\end{array}$ & UAE (26) & \\
\hline Age (years) & $32.8 \pm 4.5$ & $32.7 \pm 5.1$ & $31.4 \pm 4.4$ & 0.315 \\
\hline $\begin{array}{l}\text { Number of prior cesarean deliveries } \\
\text { I } \\
>1\end{array}$ & $\begin{array}{l}127 \\
18\end{array}$ & $\begin{array}{l}25 \\
8\end{array}$ & $\begin{array}{l}19 \\
7\end{array}$ & 0.387 \\
\hline $\begin{array}{l}\text { Time since last cesarean delivery (months) } \\
\leq 12 \\
13-120 \\
>120\end{array}$ & $\begin{array}{l}32 \\
102 \\
11\end{array}$ & $\begin{array}{l}3 \\
26 \\
4\end{array}$ & $\begin{array}{l}6 \\
18 \\
2\end{array}$ & 0.287 \\
\hline $\begin{array}{l}\text { Symptoms } \\
\text { Only amenorrhea } \\
\text { Vaginal bleeding } \\
\text { Vaginal bleeding with abdominal pain } \\
\text { Initial serum HCG (IU/L) } \\
\text { Diameter of the gestational sac }(\mathrm{mm})\end{array}$ & $\begin{array}{l}23 \\
112 \\
10 \\
148,521.5 \pm 453.1 \\
23.5 \pm 2.1\end{array}$ & $\begin{array}{l}8 \\
17 \\
8 \\
15,374.4 \pm 2 \mid 3.6 \\
31.3 \pm 2.4\end{array}$ & $\begin{array}{l}12 \\
10 \\
4 \\
14,414.7 \pm 329.4 \\
30.8 \pm 1.9\end{array}$ & $\begin{array}{l}0.101 \\
0.421 \\
0.948 \\
0.600 \\
0.024\end{array}$ \\
\hline
\end{tabular}


Table 2 Comparison Of The Parameters Of Three Different Treatment Groups

\begin{tabular}{|c|c|c|c|c|}
\hline \multirow[t]{2}{*}{ Variables } & \multicolumn{3}{|l|}{ Types Of Surgery For CSP } & \multirow[t]{2}{*}{$P$ value } \\
\hline & Transvaginal Clearance (145) & Endoscopic Surgery (33) & UAE (26) & \\
\hline Surgical time (min) & $31.4 \pm 2.5$ & $45.8 \pm 2.2$ & $51.4 \pm 1.9$ & 0.001 \\
\hline Blood loss $(\mathrm{mL})$ & $53.3 \pm 5.5$ & $105.2 \pm 3.2$ & $75.6 \pm 3.5$ & 0.001 \\
\hline Blood transfusion & $1 / 145$ & $3 / 33$ & $0 / 26$ & 0.005 \\
\hline Pelvic adhesion & $1 / 145$ & $2 / 33$ & $0 / 26$ & 0.337 \\
\hline Discomfort & $1 / 145$ & $9 / 33$ & $16 / 26$ & 0.001 \\
\hline Hospital stay (days) & $6.1 \pm 1.1$ & $7.4 \pm 0.9$ & $18.6 \pm 1.5$ & 0.001 \\
\hline Hemoglobin before surgery $(g / L)$ & $114.7 \pm 16.3$ & $115.7 \pm 17.1$ & $116.9 \pm 12.5$ & 0.798 \\
\hline Hemoglobin after surgery $(g / L)$ & $107.5 \pm 15.1$ & $104.5 \pm 14.9$ & $101.9 \pm 13.2$ & 0.158 \\
\hline Fever duration (days) & $1.0 \pm 0.5$ & $2.1 \pm 2.8$ & $5.7 \pm 3.5$ & 0.001 \\
\hline Hospital expenses (Yuan) & $7825.9 \pm 234.9$ & $10,248.3 \pm 312.9$ & $18,774.9 \pm 243.6$ & 0.001 \\
\hline
\end{tabular}

\section{Discussion}

CSP refers to an embryo implanted in the previous cesarean section scar, enveloped by uterine muscle fibers and fibrous tissues, and is becoming prevalent. It is reported that CSP may represent approximately $6 \%$ of all ectopic pregnancies in women who have undergone at least one previous cesarean section. Vaginal bleeding after amenorrhea was the most common but non-specific symptom. Some patients with CSP may simultaneously experience low abdominal pain and vaginal bleeding. Transvaginal ultrasound plays a pivotal role in the diagnosis of CSP. Special attention should be paid when the patient has a history of cesarean section. Misdiagnosis often leads to uncontrollable hemorrhage and even hysterectomy. In our study, 26 patients were misdiagnosed with intrauterine pregnancy and experienced dilatation and curettage, of whom 4 cases experienced massive hemorrhage.

Due to the lack of clinical data, there is no uniform guidelines to treat CSP and no consistent standard treatment exists. Nowadays, there are many methods to treat CSP including expectant management, dilatation and curettage with the guidance of ultrasound, direct injection of potassium chloride into the embryonic sac with the guidance of ultrasound, local or systemic injection of MTX, ${ }^{13}$ uterine artery embolization, hysteroscopy, laparotomy or laparoscopic excision..$^{9-11}$ However, none of these treatments is entirely satisfactory. In our study, we reported three different methods to control CSP and compared the clinical parameters during the procedures.

Transvaginal pregnancy tissue clearance to treat CSP was first reported by Qemer Khoshnow in 2010, during which the defect of cesarean section was well repaired and menstruation returned to normal. ${ }^{14}$ In our case, 145 patients experienced transvaginal pregnancy tissue clearance, all of them showed significant decline in serum $\beta$ HCG. Although without any pretreatment before surgery, the blood loss was lowest among the three groups. For this procedure did not enter the pelvic cavity, pelvic adhesion had no any adverse effect during the surgical course. We consider transvaginal procedure as simple, non-invasive and cheap in terms of blood loss, the rate of blood transfusion, surgical time, and hospital expense, which were lowest among the three groups. What is more, nearly no discomfort and complications appeared. Meanwhile, resection of the old scar with a new uterine closure can reduce the recurrence of scar dehiscence. ${ }^{15}$

Though high quality equipment and an experienced endoscopic surgical team are essential for the success of endoscopic surgery, it was still considered to be a minimally invasive alternative for CSP with good prognosis and preservation of fertility. ${ }^{16}$ Endoscopic surgery included hysteroscopy for visualization of the uterine cavity with incision and aspiration of the ectopic mass by operative laparoscopy. In our study, we did not perform endoscopic surgery directly, especially for patients with high level of serum $\beta$-HCG. Due to risk of uncontrollable hemorrhage, we administered MTX and/or mifepristone to patients before endoscopy. Decreased trend of serum $\beta$ HCG after the administration of MTX and/or mifepristone needs to be observed for a long time, therefore hospitalization days extended spontaneously. In addition, the surgical time and hospital expenses increased due to high requirement of equipment and surgical skill.

UAE was initially accepted as a conservative treatment for various obstetric and gynecological conditions, such as postpartum hemorrhage, uterine myoma, and cervical 
pregnancy. Recently, the use of UAE to treat CSP has been reported, which could block the blood flow of uterine arteries, decrease vascularization, and induce trophoblastic degeneration. UAE in combination with local MTX produced satisfactory results in the treatment of $\mathrm{CSP}^{7,17} \mathrm{~A}$ success rate as high as $89.4 \%$ has been reported. ${ }^{18}$ However, in our study, there were no significant changes in serum $\beta$-HCG 96 hrs after administration of UAE with local MTX, and $\beta$-HCG was increased in 4 patients who needed additional intervention. What is more, the frequency of discomfort, hospital stay, and expense were the highest of the three groups. We do not consider UAE with local MTX as a good alternative for CSP.

\section{Conclusion}

In summary, early diagnosis of CSP provides the opportunity for conservative treatment and greatly improves the prognosis of patients. Though, there is no universal agreement on the optimal treatment modality for CSP. In this retrospective study, even with selective bias, we still believe that transvaginal pregnancy tissue clearance was the preferred option for fertility-preservation approach.

\section{Funding}

The National College Students Innovation and Entrepreneurship Training Program (CX18024).

\section{Disclosure}

The authors declare that they have no competing financial interests.

\section{References}

1. Seow KM, Huang LW, Lin YH, Lin MY, Tsai YL, Hwang JL. Cesarean scar pregnancy: issues in management. Ultrasound Obstet Gynecol. 2004;23:247-253. doi:10.1002/uog.974

2. Timor-Tritsch IE, Monteagudo A. Unforeseen consequences of the increasing rate of cesarean deliveries: early placenta accreta and cesarean scar pregnancy. A review. Am J Obstet Gynecol. 2012;207:14-29. doi:10.1016/j.ajog.2012.03.007
3. Li Y, Gong L, Wu X, Gao H, Zheng H, Lan W. Randomized controlled trial of hysteroscopy or ultrasonography versus no guidance during $\mathrm{D} \& \mathrm{C}$ after uterine artery chemoembolization for cesarean scar pregnancy. Int J Gynaecol Obstet. 2016;135:158-162. doi:10.1016/j.ijgo.2016.04.019

4. Seow KM, Cheng WC, Chuang J, Lee C, Tsai YL, Hwang JL. Methotrexate for cesarean scar pregnancy after in vitro fertilization and embryo transfer. A case report. J Reprod Med. 2000;45:754-757.

5. Godin PA, Bassil S, Donnez J. An ectopic pregnancy developing in a previous caesarian section scar. Fertil Steril. 1997;67:398-400. doi:10.1016/S0015-0282(97)81930-9

6. Persadie RJ, Fortier A, Stopps RG. Ectopic pregnancy in a caesarean scar: a case report. J Obstet Gynaecol Can. 2005;27:1102-1106.

7. Sugawara J, Senoo M, Chisaka H, Yaegashi N, Okamura K. Successful conservative treatment of a cesarean scar pregnancy with uterine artery embolization. Tohoku J Exp Med. 2005;206:261265. doi:10.1620/tjem.206.261

8. Yang MJ, Jeng MH. Combination of transarterial embolization of uterine arteries and conservative surgical treatment for pregnancy in a cesarean section scar. A report of 3 cases. J Reprod Med. 2003;48:213-216.

9. Siedhoff MT, Schiff LD, Moulder JK, Toubia T, Ivester T. Roboticassisted laparoscopic removal of cesarean scar ectopic and hysterotomy revision. Am J Obstet Gynecol. 2015;212:681.e681-684. doi:10.1016/j.ajog.2014.12.004

10. Wang DB, Chen YH, Zhang ZF, et al. Evaluation of the transvaginal resection of low-segment cesarean scar ectopic pregnancies. Fertil Steril. 2014;101:602-606. doi:10.1016/j.fertnstert.2013.10.024

11. Wang G, Liu X, Bi F, et al. Evaluation of the efficacy of laparoscopic resection for the management of exogenous cesarean scar pregnancy. Fertil Steril. 2014;101:1501-1507. doi:10.1016/j.fertnstert.2014.01.045

12. Ash A, Smith A, Maxwell D. Caesarean scar pregnancy. BJOG. 2007;114:253-263. doi:10.1111/j.1471-0528.2006.01237.x

13. Liu G, Wu J, Cao J, et al. Comparison of three treatment strategies for cesarean scar pregnancy. Arch Gynecol Obstet. 2017;296:383389. doi:10.1007/s00404-017-4426-5

14. Khoshnow Q, Pardey J, Uppal T. Transvaginal repair of caesarean scar dehiscence. Aust N Z J Obstet Gynaecol. 2010;50:94-95. doi:10.1111/j.1479-828X.2009.01107.x

15. Fylstra DL, Pound-Chang T, Miller MG, Cooper A, Miller KM. Ectopic pregnancy within a cesarean delivery scar: a case report. Am J Obstet Gynecol. 2002;187:302-304. doi:10.1067/mob.2002.125998

16. Wang CJ, Chao AS, Yuen LT, Wang CW, Soong YK, Lee CL. Endoscopic management of cesarean scar pregnancy. Fertil Steril. 2006;85:494.e491-494. doi:10.1016/j.fertnstert.2005.07.1322

17. Ghezzi F, Lagana D, Franchi M, Fugazzola C, Bolis P. Conservative treatment by chemotherapy and uterine arteries embolization of a cesarean scar pregnancy. Eur $J$ Obstet Gynecol Reprod Biol. 2002;103:88-91. doi:10.1016/s0301-2115(02)00003-9

18. Yang XY, Yu H, Li KM, Chu YX, Zheng A. Uterine artery embolisation combined with local methotrexate for treatment of caesarean scar pregnancy. BJOG. 2010;117:990-996. doi:10.1111/j.1471-0528.2010.02578.x

Therapeutics and Clinical Risk Management

Dovepress

\section{Publish your work in this journal}

Therapeutics and Clinical Risk Management is an international, peerreviewed journal of clinical therapeutics and risk management, focusing on concise rapid reporting of clinical studies in all therapeutic areas, outcomes, safety, and programs for the effective, safe, and sustained use of medicines. This journal is indexed on PubMed Central, CAS,
EMBase, Scopus and the Elsevier Bibliographic databases. The manuscript management system is completely online and includes a very quick and fair peer-review system, which is all easy to use. Visit http://www.dovepress.com/testimonials.php to read real quotes from published authors. 